\title{
Emancipación, hegemonía y autonomía relativa del derecho.
}

\author{
Emancipation, hegemony and relative autonomy of law. \\ Carlos Lascarro Castellar \\ Diemer Lascarro Castellar ${ }^{2}$ \\ Sergio Caballero Palomino ${ }^{3}$
}

RESUMEN

El presente artículo tiene como objetivo general rastrear el estado del arte sobre el concepto de emancipación desde el constitucionalismo. Está delimitado al caso colombiano, aunque toma en varios puntos teorías foráneas. Para lograr ese objetivo, como estrategia metodológica se ha optado por dividir el texto en tres partes: la primera indaga sobre la categoría de emancipación desde el liberalismo, el marxismo y desde una tercera opción mixta. La segunda parte, responde la pregunta sobre la capacidad de emancipación social en la jurisprudencia constitucional. Finalmente, la tercera parte rastrea los límites de la emancipación desde cuatro lecturas: una cercana al marxismo, desde la teoría jurídica, el análisis económico del derecho y una cuarta opción radical. Al final, se ofrecen unas conclusiones generales.

\section{Palabras claves:}

Activismo judicial, Emancipación, Hegemonía y Jurisprudencia Constitucional.

\footnotetext{
${ }^{1}$ Magister en Derecho por la Universidad Nacional de Colombia. Profesor TC de la Facultad de Ciencias Jurídicas de la Universidad del Atlántico. Carloslascarro@mail.uniatlantico.edu.co.

${ }^{2}$ Magister en Derecho por la Universidad Nacional de Colombia. Profesor TC de la Facultad de Ciencias Jurídicas de la Universidad del Atlántico. Diemerlascarro@mail.uniatlantico.edu.co.

${ }^{3}$ Especialista en Derecho Administrativo. U. Libre. Maestrando en Derecho del Estado. U. Externado. Docente de Especialización en Derechos Humanos. Par Académico Ministerio de Educación Nacional. abogadosergiocaballero@hotmail.com.
}

Recibido: 2 de marzo de 2019. Aprobado: 13 de Mayo de 2019. 


\begin{abstract}
:
The present article has as general objective to trace schematically the state of the art on the concept of emancipation from the right. It is delimited to the Colombian case, although it takes in several points foreign theories. To achieve this general objective the text has been divided into three parts: the first investigates the category of emancipation from liberalism, Marxism and a third mixed option. The second part answers the question about the capacity for social emancipation in constitutional jurisprudence. Finally, the third part traces the limits of emancipation from four readings: one close to Marxism, from legal theory, the economic analysis of law, and a fourth radical option.
\end{abstract}

\title{
Key words:
}

Judicial activism, Emancipation, Hegemony and Constitutional Jurisprudence.

\section{Introducción}

El concepto de emancipación está ubicado como una categoría analítica del marxismo ${ }^{4}$. Categoría que es entendida como la capacidad de transformación social, por medio de la política, del medio existente o lo que es lo mismo del statu quo. Ello significa entonces, que la estructura básica del estado, "estado liberal” o "estado de derecho", debe ser transformado en un sistema político justo, sea comunismo o sea socialismo. En ese sentido, el estado liberal plantea, por medio del derecho, un sistema desigual y no universal (como frecuentemente suele ser analizado). Desigual porque establece y legaliza la división de la sociedad en clases, burguesía y proletariado. En donde uno de estos, el primero, detenta los medios de producción, mientras que el otro solo posee la mano de obra que es explotada en la fábrica. $Y$ no universal porque, como señala Beatriz González Stephan (1996), el estado de derecho moderno se materializa mediante la categoría de "ciudadanía", la cual se erige sobre la construcción de perfiles de subjetividad estatalmente coordenados. Es decir, que solo es ciudadano aquel sujeto que cumple con los requerimientos de la escritura disciplinaria de las constituciones,

\footnotetext{
${ }^{4}$ No hago referencia a Kant porque, en este trabajo, nos enfocaremos en la categoría de emancipación únicamente en lo que guarda relación, directa o indirectamente, con el derecho.
} 
los manuales de urbanidad y las gramáticas de la lengua. El sujeto de derecho entonces es blanco, propietario, letrado, habla español, católico, hombre y de buenos modales. Todas aquellas subjetividades que no logren cumplir con los requisitos del sujeto moderno quedan alojadas por fuera de la cuidad jurídica; quedan instituidos en la ilegalidad. Indígenas, afros, raizales, indigentes, gitanos y mestizos son entendidos como subculturas que deben re ajustar sus perfiles de subjetividad. Así las cosas, el derecho deviene en un instrumento de dominación con fines exclusivamente hegemónicos. De ahí que se diga, que seguir estrategias jurídicas (reformas legales o litigio constitucional) para transformar la sociedad sea un fetiche. Es lo que la tradición marxista denomina como "fetichismo legal". Es decir, el derecho esconde, tras las normas jurídicas, en especial las constituciones, una sociedad excluyente, clasista e individualista. Al sujeto entonces se le presenta una dualidad entre, por un lado, las normas jurídicas que sostienen un derecho a la igualdad, a la libertad y un sistema democrático, y, por el otro lado, una realidad que empaña dichas normas. Hay una especie de dicotomía entre fantasía (el derecho) y la realidad material concreta. En esta dicotomía el fetichista se queda con la fantasía. Recordemos la estructura básica del deseo freudiano (ejemplificada en la célebre frase de Octave Mannoni): "Yo se... Y sin

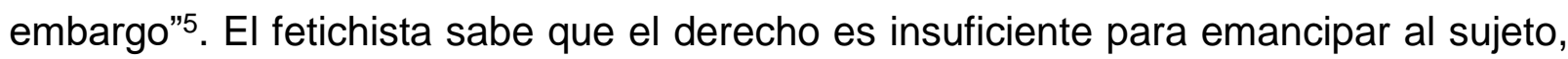
sin embargo insiste en él porque se le presenta una de-negación de la realidad: "De manera que cuando al fetichista se le dice que su objeto no es "real" (el derecho) "que no tiene sentido tener un apego tal al objeto equivocado, el fetichista ya lo sabe, y sin embargo lo desea, y lo goza" (Ripoll, 2016, pág. 388). En síntesis, esta primera lectura marxista entiende la emancipación como un proceso eminentemente político y no jurídico. El derecho, desde esta óptica, tiene un contenido a priori el cual es un uso hegemónico; a lo máximo podría lograr ciertas reivindicaciones para los movimientos sociales, pero no emancipación.

\footnotetext{
${ }^{5}$ Véase Lemaitre $(2016,389)$.
} 
La segunda lectura que podemos rastrear sobre la categoría de emancipación se encuentra en lo que Jean François Lyotard (1987) va a llamar como el segundo metarrelato de la modernidad (siendo el primero el marxismo y el tercero el cristianismo). Cuando decimos metarrelatos hacemos referencia a los distintos proyectos políticos o ideológicos que, con una consolidada hegemonía, guiaron la mente de los sujetos para la construcción de su mundo desde aproximadamente el siglo XVIII, específicamente, en lo que, más allá de las discusiones a las que puede conllevar el término, se ha dado en Ilamar la "modernidad". En otras palabras, los metarrelatos son los proyectos por medio de los cuales se podía pensar la sociedad, la política, el derecho e incluso la emancipación desde el citado periodo histórico. En concreto, para el liberalismo el derecho constituye perse un instrumento de liberación, de emancipación: es el mecanismo por medio del cual, por ejemplo, las poblaciones latinoamericanas en el siglo XVIII pudieron, a través de sus cartas constitucionales, liberarse de la subordinación de las élites hispano lusitanas. Las constituciones en ese sentido liberan, proclaman derechos no reconocidos, crean instituciones democráticas, delimitan el poder y establecen competencias. Como diría Tomas Hobbes permiten el trance del estado de naturaleza a la sociedad civil. Del caos, los dientes, las garras, el nomadismo, la especulación y la violencia hacia el orden, las buenas costumbres, la ciencia, la civilización y el orden justo que impone el derecho. Ya no es necesario ir a las calles a hacer la revolución; tampoco desgastar al poder constituyente (el pueblo) a que despliegue todo su arsenal violento. Ya no. La existencia del estado permite institucionalizar la libertad (para parafrasear a Hegel). Cuerpos colegiados que representan al poder constituyente y reflejan su voluntad. Estos cuerpos colegiados, estructurando al Estado (poder legislativo, judicial y ejecutivo), en el poder constituido, desencadenan un fuerte potencial emancipatorio de la forma jurídica: materializan la capacidad innata del derecho. Los problemas sociales, por muy complejos que sean, tienen un espacio para su solución. Ese espacio es el estado: el lugar donde se pueden resolver y conciliar los antagonismos.

Hasta aquí dos caras (radicales) de la moneda: una emancipatoria y otra hegemónica. Sin embargo, es posible construir una tercera opción mixta o más bien neutral. Su 
importancia radica básicamente en que se constituye en una opción que evita la construcción de a prioris, o pre juicios sobre la función o uso del derecho, es decir, sobre su capacidad de transformación social. Es necesario advertir, aunque ya los lectores posiblemente lo supondrán, que es esta la versión más dominante en la academia sobre el uso o contenido del derecho. Quisiera ilustrar este punto acudiendo a la idea de los derechos entendidos como "significantes multiformes e irresueltos" o como "significantes vacíos". Es decir, que la función de los derechos no se puede construir bajo premisas dadas de ante mano. Sino que esta depende de factores tales como el tiempo, las culturas y las relaciones de poder en determinado especio geográfico y temporal. En ese sentido estos operan, tal como señala Brown (2003, pág. 83)

"en y como un idioma ahistórico, acultural y acontextual... Esta paradoja entre el idioma universal y el efecto local de los derechos trasciende tanto a niveles temporales como a los espaciales: si bien los derechos pueden operar como una indiscutible fuerza emancipatoria en un momento de la historia..., en otro momento pueden volverse un discurso regulador, un medio para obstruir o cooptar demandas políticas más radicales, o ser simplemente las más hueca de las promesas vacías".

Un ejemplo frecuentemente utilizado (ver: Brown, 2003; Jaramillo, 2003 y Villegas, 2016) para ilustrar la fuerza emancipatoria de los derechos, suelen ser los logros obtenidos por el denominado Civil Rights Movement en los Estados Unidos a principios del siglo XX. Movimiento que obtuvo conquistas jurídicas que se tradujeron en la protección de los ciudadanos de color negro, acceso al sufragio y a la justicia ante los tribunales, entre otros. O, para ejemplificar mediante casos latinoamericanos, los recientes procesos constitucionales en Bolivia y Ecuador, que dieron como resultado la creación de derechos y principios tales como el Estado Plurinacional (Médici, 2010 y 
Baldi, 2013), la descolonización ${ }^{6}$, la revitalización del poder constituyente (Martínez \& Viciano, 2010) entre otros logros más. Un ejemplo contrario, donde los derechos no parecen haber significado conquistas para los grupos históricamente excluidos, es la Constitución de Perú de 1993, la cual se expidió durante un gobierno autoritario como el de Alberto Fujimori y que además implantó, en términos generales, un modelo económico neoliberal que trajo consigo recortes serios en materia de derechos. $\mathrm{O}$ incluso la Constitución colombiana de 1886, la cual, como en muchos países de América Latina, funcionó como una "carta de batalla" (Valencia, 1987) en donde, u operaba la ideología del partido triunfante, liberal o conservador, o simplemente se consignaba un acuerdo entre el bipartidismo, como en el caso del Frente Nacional. El discurso de los derechos opera entonces bajo una "autonomía relativa", donde la balanza, a pesar de tender a inclinarse hacia la dominación, siempre queda un espacio para que los sujetos por medio de las instituciones puedan realizar reivindicaciones. De ahí que, algunos autores como Roberto Gargarella, Rodrigo Uprimny y Daniel Kommers, planteen que, por ejemplo, el contenido de las constituciones no es susceptible de determinarse mediante un juicio a priori, es decir ni son emancipatorias o instrumentales por naturaleza, sino que este contenido depende de ciertos factores como lo son el apoyo de las fuerzas políticas dominantes y la presencia de procesos de democracia deliberativa (Villegas, 2016).

De lo anterior se derivan al menos tres hipótesis básicas: la primera, es que pueden existir constituciones garantistas y ricas en derechos que terminen, por la excesiva concentración del poder ejecutivo, por procesos poco o nada democráticos o por la falta de apoyo de fuerzas políticas, generando decisiones regresivas en materia de derechos. En este caso, los logros planteados en la (redacción de la) constitución, sufren un fuerte reverso en la interpretación de la misma. Hay entonces una desconexión entre poder constituyente y poder constituido. La segunda hipótesis es

\footnotetext{
${ }^{6}$ Sobre este punto véase el innovador trabajo de Diemer Lascarro; donde intenta estructurar la forma en que los estudios constitucionales han tenido un contacto con los estudios decoloniales. Además de ello, el autor expone los límites de ese acercamiento y posibles formas para superar los mismos (Lascarro D. , 2016) .
} 
contraria a la anterior: una constitución redactada dentro de unos parámetros pobres en derechos y poco garantista puede eventualmente ser re interpretada, por ejemplo, por vía jurisprudencial, y de esta forma incorporar nuevos derechos. Aquí, mientras el poder constituyente fue egoísta en reconocer derechos, el poder constituido fue generoso al respecto.

Ahora bien, de estas dos primeras hipótesis pueden presentarse dos variantes las cuales están referidas al contenido de la constitución (progresista o más bien egoísta en derechos): la primera es que en el proceso de creación de la constitución solo participen las fuerzas políticas dominantes de la época. A esto lo llamaremos "constitucionalismo de élites". Y la segunda, es que actores como movimientos sociales, grupos minoritarios y población en general, junto con partidos políticos dominantes intervengan conjuntamente en el proceso de creación constitucional. A esto lo llamaremos "constitucionalismo democrático". La tercera y última hipótesis que podría darse sería el continuismo. Me explico. Una constitución conservadora o de avanzada en su redacción se mantiene como tal en su interpretación. Aquí, contrario a las dos primeras hipótesis, sí hay una conexión entre poder constituyente y poder constituido.

\section{Emancipación social y luchas jurídicas a través del derecho (constitucional)}

Quisiera en esta segunda parte del trabajo indagar sobre la capacidad y los límites de la emancipación social desde el derecho. Trataré de ilustrar desde la jurisprudencia de la Corte Constitucional colombiana ese potencial emancipatorio. Para ello, me basaré en el trabajo de Mauricio García Villegas y Rodrigo Uprimny, y en general, en algunas reflexiones de la sociología jurídica colombiana. Tomaré como centro de análisis los conceptos de activismo judicial y justicia constitucional. Al final, cerraré presentando algunos desajustes que creo son necesario explorar con respecto al tema.

Uno de los documentos icónicos dentro del tema es sin duda alguna el trabajo de Mauricio García Villegas y Rodrigo Uprimny. Los autores, que podríamos catalogar 
como dos de los principales representantes de la sociología jurídica en Colombia (uno estaría tentado de hablar de la Uprimny's Schoo/'), intentan medir el potencial emancipatorio de la jurisprudencia constitucional a partir de cuatro casos concretos. Es necesario advertir que el concepto de emancipación utilizado no es el del marxismo, ni el del liberalismo, es más cercano a la tercera opción: "aquí adopto" dice Mauricio García (Villegas, 2016, pág. 215) "una concepción amplia y débil del concepto de emancipación. El derecho no hace las revoluciones; más bien es lo contrario lo que ocurre: el derecho impide que las revoluciones se hagan. No obstante, puede haber usos del derecho que, bajo ciertas circunstancias produzcan cambios sociales importantes y hasta revolucionarios. Una visión amplia y débil del concepto de emancipación permite ver eso: incluir una serie de luchas sociales progresistas con un alcance reformador que pueden, en el mediano y largo plazo, producir cambios transformadores". Esa sería entonces una de las principales funciones del activismo judicial: producir cambio social en materia de grupos poblacionales que difícilmente tienen acceso a los derechos y que históricamente han sido subordinados. Ese activismo judicial, para poder consolidarse, tendría que presentar básicamente tres fundamentos, que le permitan a su vez legitimarse. El primero y el tercero están relacionados con un tema de cultura jurídica, mientras que el segundo con un tema político o institucional. Para que los jueces se puedan tomar en serio los derechos es necesario realizar un ajuste de paradigma en la forma de entender el sistema o familia jurídica. Ese ajuste va a evidenciarse, en términos de cultura jurídica, a partir de la expedición de la Constitución de 1991. Y puede resumirse como el "trance" del estado de derecho al estado constitucional. Es decir, sino se revalúa el modelo positivista no es posible entender porque los jueces pueden desplegar funciones que en principio no

\footnotetext{
${ }^{7}$ Con Uprimny's School me refiero a aquel conjunto de académicos, juristas, activistas y estudiantes tanto de pregrado como de posgrado, que, tomando como centro de acción ideas del profesor Rodrigo Uprimny han logrado consolidar una hegemonía relativamente estable y un considerable capital social o prestigio dentro de los círculos académicos e institucionales. Cuando digo que se han articulado, hago referencia a que su centro de acción puede ser localizado: Dejusticia, la Facultad de Derecho de la Universidad Nacional, particularmente por medio de ciertas cátedras donde la Uprimny's School ha tomado una hegemonía absoluta. Y podríamos citar incluso algunos círculos de la Universidad de los Andes, en su Facultad de Derecho.
} 
le estarían encomendadas por la carta constitucional. El formalismo, propio de las familias de derecho germano románico o civil law planteaba que era el legislador, y no el poder judicial a través de sentencias como suele suceder en el commom law, quien debía formular los principales cambios sociales por medio de la ley. El juez solo aplicaba la norma ya que el derecho es un sistema cerrado y completo: tiene la capacidad de regular toda la complejidad social. Esta forma de entender el derecho pasa a ser fuertemente revaluada por la teoría (López, 2016) y la sociología jurídica en Colombia (Encinales, 2011). Para finalmente plantear que, este sería el segundo fundamento, de tipo político, que los jueces, ante un vacío institucional, tienen la obligación de actuar para dar cumplimiento a los mandatos constitucionales. Dicho vacío se presentaría cuando algunos poderes públicos como el legislativo no ejecutan funciones propias de estos mandatos. Allí entonces parecer perder fuerza la tesis de la famosa "dificultad contra mayoritaria" del poder judicial de la que hablaba Alexander Bickel, dificultad que le restaría legitimidad al activismo judicial ${ }^{8}$.

Un tercer fundamento en torno al activismo judicial, que como ya habíamos mencionado le permite reforzar sus procesos de legitimación, gira en la pregunta por qué se cree en los derechos y en el discurso de los derechos (más que en el discurso político, por ejemplo). Existen varias respuestas a esta pregunta. La primera tiene que ver con el lugar privilegiado que ocupan los derechos en la teoría jurídica en Colombia (Jaramillo, 2003). Esta teoría jurídica que ha tomado como armazón doctrinas foráneas de autores como Alexy, Dworkin, Habermas, Nino y Atienza ha puesto un notable énfasis en el poder judicial y su capacidad para incorporar nuevas categorías (ponderación, principio de proporcionalidad, efecto irradiador de los derechos fundamentales...) que expliquen

\footnotetext{
${ }^{8}$ Un ejemplo de ese vació institucional al que hacemos referencia puede ilustrarse en el caso colombiano frente al tema del desplazamiento forzado. Condición que apenas cambia desde la expedición y posterior implementación de la Sentencia T-025 de 2004. Al respecto señalan César Rodríguez y Diana Rodríguez (Rodríguez, 2012, pág. 43): "aunque existía un marco jurídico y unos documentos preliminares de política que regulaban el tema, en la práctica estos se quedaban en el papel". Es decir, el manejo institucional en materia de desplazamiento era precario. "En últimas, desde un punto de vista constitucional, un vacío de política pública de este tipo es relevante en la medida en que contribuya a perpetuar (o, incluso, profundizar) violaciones graves y reiteradas de derechos humanos". Este punto lo retomaremos más adelante.
} 
de manera satisfactoria la realidad constitucional post-91 en Colombia. Este ha sido entonces el trabajo de la teoría jurídica nacional, de la mano de autores como Diego López Medina, Carlos Bernal Pulido y Rodolfo Arango. Esa labor es reforzada desde un segundo flanco, el de la sociología jurídica, el cual hace énfasis en la forma en que las clausulas constitucionales progresistas son materializadas por vía judicial. Aquí serán resonados los nombres de autores como Rodrigo Uprimny, Mauricio García, César Rodríguez, Julieta Lemaitre y Diana Rodríguez. Un tercer flanco que apoya este activismo judicial se ha construido desde lo que podríamos llamar los estudios multiculturales del derecho (Lascarro C., 2012). Desde autores como Daniel Bonilla Maldonado se ha insistido en rastrear la forma en que la Corte Constitucional resuelve el complejo problema de la diversidad cultural. Estas tres lecturas buscan entonces reforzar el rol del tribunal constitucional y su capacidad de transformación social. Una cuarta lectura que apoya directa o indirectamente este tipo de activismo judicial es lo que uno estaría tentado de llamar el tradicionalismo. Es decir, la forma en que tradicional y usualmente se enseña derecho constitucional en las facultades de derecho de Colombia. Esto se hace básicamente de dos formas: desde una perspectiva histórica, que pone un fuerte énfasis en el constitucionalismo del siglo XVIII, Francia, Norte América e Inglaterra principalmente; y una línea institucional, que se enfoca, primero, en la parte dogmática de la constitución, y segundo, en la parte orgánica de la misma. En la primera línea podemos encontrar autores como Andrés Botero Bernal, Bern Marquart y en la segunda autores como Carlos Restrepo Piedrahita?.

Una segunda explicación a la pregunta de la creencia en el discurso de los derechos, tiene que ver con cifras: uno de cada diez colombianos ha interpuesto, con independencia del resultado de la acción, al menos una vez en su vida una acción de tutela. Una tercera explicación está relacionada con el apoyo que ha recibido la Corte por parte de la opinión pública. Como es ampliamente conocido el tribunal constitucional colombiano goza de un reconocido prestigio que ha conseguido luego de la

\footnotetext{
${ }^{9}$ Sobre toda esta discusión y la idea de lecturas o perspectivas constitucionales, véase Lascarro, 2016; allí presento de manera muy esquemática la bibliografía que apenas referencia en este píe de página.
} 
Lascarro Castellar, C; Lascarro Castellar, D; Caballero Palomino, S. 11

intervención, en muchos casos polémica, en diferentes aspectos neurálgicos del contexto colombiano (casos como los del aborto, la eutanasia, el matrimonio y la adopción de personas del mismo sexo, la reelección presidencial del segundo periodo del gobierno Uribe, entre otras). Eso hace que la Corte sea vista como uno de los principales canales de comunicación entre el poder constituyente y el poder constituido.

\section{Jurisprudencia Emancipatoria}

En ese sentido, García Villegas y Uprimny intentan mostrar el potencial emancipatorio de la jurisprudencia constitucional, a partir de cuatro casos: El primero es el movimiento social indígena; el cual mediante diversos pronunciamientos de la Corte Constitucional ha alcanzado numerosas reivindicaciones en materia de derechos. Como ejemplo de ello, pueden citarse algunos casos jurisprudenciales referidos al conflicto entre los antagonismos cultural y económico: el primero representaría la diversidad cultural, la existencia misma de los pueblos indígenas y lo que algunos autores han denominado como el "antagonismo verde", mientras que el segundo podría leerse como una expresión de las políticas neoliberales que buscan beneficiar cada vez más a instancias internacionales. Ello se expresa cuando la Corte decide proteger al pueblo U'WA de los intentos de la transnacional OXI de explotar petróleo en zonas sagradas de esta comunidad. De igual forma, ha protegido el derecho a la consulta previa en numerosas ocasiones; como cuando declaró la inconstitucionalidad del Estatuto de Desarrollo Rural en 2007. Los líderes y movimientos indígenas han dado cuatro lecturas frente a este activismo judicial: la primera puede catalogarse como una visión optimista, la cual considera que dichas decisiones constituyen "grandes triunfos". La segunda es más bien neutral en la medida en que ve en el activismo judicial no grandes logros sino más bien "obligaciones que cumple la Corte Constitucional". La tercera es más bien pesimista, pues entiende la vía jurisprudencial como una "estrategia errónea"; la correcta sería negociar con el gobierno. Finalmente, el fundamentalismo indígena, visualiza el derecho como un mero instrumento de presión (Villegas, 2016, pág. 180). 
El segundo caso analizado es el del movimiento sindical; el cual, desde los años setenta utilizó la estrategia ideológica como forma de combate, re realizar sus demandas: esto incluía básicamente la protesta social y las huelgas, las cuales daba como resultado, en algunos casos, convenciones colectivas del trabajo firmadas entre empleador y trabajadores. Esta estrategia sin embargo parecía no dar resultado, máxime si se tiene en cuenta que para la época otros factores tales como la crisis generalizada de la izquierda en la región, la implantación acelerada de las políticas neoliberales y los crecientes procesos de violencia contra los sindicalistas agudizaban la crisis del movimiento. Ante ello, el movimiento decide optar por una estrategia mixta, la cual utilizara también la lucha jurídica. Es así como se intenta por medio de acciones de tutelas lograr el restablecimiento de derechos. Ejemplo de ello, son las Sentencias T568 de 1999 y T-436 de 2000 por medio de las cuales se logra el reintegro, pagos de salarios no devengados, pagos de seguridad social e indemnizaciones de 209 y 2000 trabajadores, respectivamente, que habían sido desvinculados con el cumplimiento del régimen legal más no constitucional. La Corte operó aquí como símbolo de esperanza de cambio social y última instancia a la que podían acudir los sindicatos. El tercer espacio de emancipación social se da frente al movimiento LGBTI. Toda esta jurisprudencia puede ser considerada histórica y profundamente transformadora, en la medida en que son decisiones que crean derechos jamás reconocidos por otras instancias estatales. La Corte reconoce, casi que, en una especie de gesto contra cultural, los siguientes derechos a parejas del mismo sexo: unión marital de hecho (Sentencia C-075 de 2007), la afiliación en salud (Sentencia T-856 de 2007), alimentos (Sentencia C-789 de 2008), pensión de sobreviviente (Sentencia T-051 de 2010), constituir familia, (Sentencia 577 de 2011) y finalmente constituir matrimonio y adoptar, en 2016. El cuarto movimiento social analizado es el UPAC (unidad de poder adquisitivo constante). Alrededor de 1997 un grupo de 200 familias se ven ante la eventualidad de perder sus viviendas, las cuales habían adquirido por préstamos bancarios. Las altas tasas de intereses y otros factores relacionados con las normas que regulaban dichos préstamos habían generado tal situación. Ante ello, las familias deciden optar por una estrategia política, la cual consistía en la protesta social (para visibilizar su problemática) y resistirse a la entrega de las viviendas. Esa iniciativa de desobediencia 
civil parecía no dar frutos, razón por la cual deciden manifestar su inconformismo ante el Congreso y el poder ejecutivo, lo cual tampoco funcionó. Ante tal situación optan, como última estrategia, la lucha jurídica ante el tribunal constitucional, el cual, por medio de la resolución de acciones de tutela y acciones públicas de inconstitucionalidad, entre 1998 y 1999 "profirió entonces varias sentencias sobre el sistema Upac, que en general tendían a proteger a los deudores hipotecarios. Así, la Corte vinculó el Upac a la inflación, prohibió la capitalización de intereses y ordenó que se reliquidaran los créditos para aliviar la situación de los deudores" (García, 2016, 189). A partir de las decisiones tomadas por la Corte se produjeron diferentes efectos: 1) el Congreso aprobó en 1999 una nueva ley incorporaba numerosos alivios para los deudores; 2) la estrategia jurídica definió el papel del movimiento social: una especie de "desobediencia civil judicializada y apoyada en argumentos constitucionales"; 3) las quejas individuales de los deudores se transformaron en un cuestionamiento colectivo, entre otros (Villegas, 2016).

Ahora bien, esa capacidad de la emancipación social presenta unos límites; límites que derivan de cinco factores específicos que potencializan o disminuyen la fuerza emancipatoria de la jurisprudencia constitucional. El primero está relacionado con el tipo de decisión u órdenes emitidas por la Corte y el tipo de activismo judicial que estas generan. Básicamente son dos tipos de activismo judicial: uno ideológico, que puede ser innovador o preservador: el primero crea derechos (como en el caso de los derechos credos en sede judicial para movimientos LGBTI en materia de adopción, matrimonio, unión marital de hecho, derechos al libre desarrollo de la personalidad en parejas homoparentales, entre otros) mientras que el segundo busca mantenerlos en el tiempo. El segundo tipo de activismo judicial es el remedial, que puede ser positivo o negativo: uno funciona por medio de órdenes de hacer (como cuando se ordena mejorar las condiciones de las personas en las cárceles o revisar los manuales de convivencia de los colegios con el fin de establecer si estimulan o no ambientes escolares desiguales en materia de género) y el otro por medio de prohibiciones (como en el caso del aborto, donde se prohíbe tipificar el delito en los casos de malformación del feto, peligro en la salud de la madre o por violación de esta). Como se podrá observar, el activismo remedial negativo es más fácil de ejecutar que un mandato de hacer, el cual depende 
Lascarro Castellar, C; Lascarro Castellar, D; Caballero Palomino, S. 14

de factores como la voluntad política de la administración, el presupuesto disponible, entre otros factores. El activismo ideológico es mucho más complejo de ejecutar; pues una vez creado el derecho es muy posible que aparezcan fuerzas políticas opuestas y generen una tensión tendiente a lograr reformas regresivas; implica también el diseño y ejecución de políticas públicas para materializar la sentencia; incluso depende del apoyo que la creación de tal derecho tenga de parte de la opinión pública. El segundo factor tiene que ver con el entorno de la decisión y los costos políticos de la misma. En entornos consensuales, donde existen acuerdos mínimos sobre los valores predominantes en una sociedad será más fácil ejecutar una decisión judicial por ejemplo en materia de derechos LGBTI. Mientras que entornos sin tales consensos, será más complejo. A su vez, la Corte al tomar decisiones progresistas que afecten por ejemplo élites económicas, como en el caso UPAC, se ve enfrentada a ciertos riesgos que pueden presentarse al menos de dos formas: a) eventuales reformas constitucionales que supriman facultades de la Corte Constitucional (por ejemplo, que se le prohíba al tribunal constitucional intervenir activamente en asuntos económicos), o b) que por medio de la elección de magistrados, proceso que le compete al presidente y al congreso, se seleccionen magistrados con fuertes tendencias conservadoras, los cuales pugnen por lograr cambios jurisprudenciales regresivos en materia de derechos. El tercer vector está relacionado con los receptores de la decisión. No es lo mismo cuando el movimiento social presenta una coherencia interna a que cuando se encuentra disperso y no existe entre sus miembros unanimidad sobre la formulación de sus demandas sociales. El cuarto aspecto tiene que ver con el peso de la estrategia jurídica; en algunos movimientos sociales esta es coyuntural (como en los sindicatos) mientras que en otros es constitutiva (como en los grupos LBGTI). El último aspecto guarda relación con la dimensión internacional. En algunos casos las decisiones de la Corte tienen un respaldo internacional, como sucedió en materia de derechos de los pueblos indígenas frente a la consulta previa por parte de la IOT mediante el Convenio 123; mientras que en materia de sindicatos no ha sucedido tal situación. En síntesis, una decisión judicial que expida una orden de prohibición o mandato de no hacer, que goce de respaldo internacional, que el movimiento receptor presente una coherencia interna y una estrategia jurídica constitutiva y además exista respaldo de la opinión 


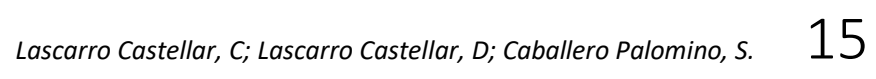

pública, posiblemente su ejecución no generará mayor traumatismo. Pero si es una decisión judicial que emita una orden de hacer, no goce respaldo de la opinión pública ni de la comunidad internacional es muy posible que su ejecución se postergue o incluso no se materialice (Villegas, 2016, págs. 191-204).

Críticas a la jurisprudencia emancipatoria en Colombia

En esta última parte, me voy a concentrar en estructurar, en el campo de estudios en Colombia, las diferentes posiciones críticas que se pueden articular cuando nos preguntamos por la capacidad de emancipación del derecho. Cada una de estas posiciones conformaría una lectura de la emancipación. Hasta donde les he podido seguir el rastro, podríamos hablar de al menos unos cuatro enfoques: a) uno primero, el cual se concentra en analizar de manera directa e indirecta dicha capacidad de emancipación de la jurisprudencia constitucional, desde una lectura cercana a la filosofía política: muy próxima a las tesis marxistas. Me refiero, en principio, al trabajo del profesor de la Universidad Nacional Oscar Mejía Quintana y algunos documentos del colectivo ILSA (Instituto Latinoamericano para una sociedad y un Derecho Alternativos). Concretamente a dos argumentos centrales: a) Mejía Quintana (Mejía, 2009) ha sostenido, en contra vía a la posición adoptada por Uprimny y García, que la jurisprudencia constitucional no puede generar un efecto emancipatorio o contra hegemónico, sino apenas reivindicatorio. La emancipación, al igual que en Marx, es solamente política no jurídica. De esta forma, el autor intenta problematizar "el carácter emancipatorio que ha querido endilgársele a la Constitución del 91 mostrando que, tras esa apariencia, se esconde un proyecto de exclusión hegemónica con el cual las élites colombianas han perpetuado su esquema histórico de dominación" (Mejía. 2003, 1): los derechos son, entonces, el escudo argumentativo y simbólico para lograr imponer la dominación hegemónica, la cual, a través de la jurisprudencia podría amarrar las potencialidades emancipatorias efectivas y reales, necesariamente políticas y contestatarias, a sencillos, pero absolutamente engañosos espejismos jurídicos (Mejía, 2009). A pesar de ello, el autor reivindica el papel de la jurisprudencia constitucional, es decir, no niega que algunas prácticas jurisprudenciales generen avances. Lo que le 
Lascarro Castellar, C; Lascarro Castellar, D; Caballero Palomino, S. 16

preocupa es denunciar la forma como ha operado el discurso de los derechos, los cuales son presentados como instrumentos de resistencia, cuando, en realidad, dicho discurso ha intentado desapercibir el dispositivo hegemónico que yace en ellos. B) El segundo argumento, quizás el punto más álgido señalado por Mejía, es poner de manifiesto cómo la Corte constitucional, mediante ciertas tensiones y desplazamientos, "sufre" un giro: de la jurisprudencia de claro corte social a una jurisprudencia de explícito carácter neoliberal (Mejía y Galindo, 2006, pág. 384). En este tipo de críticas se reconocen los avances significativos de la actual Carta con respecto a la de 1886, pero también se insiste en que dentro de la jurisprudencia coexisten varios modelos que no solamente son diferentes sino contradictorios. Esta contradicción va a evidenciarse de manera desastrosa en la medida en que el juez constitucional debe dar aplicación a los principios que emanan de uno y otro modelo, pues ambos son cartas de triunfo y mandatos de optimización, respectivamente. Inicialmente, la primera y la segunda Corte Constitucional van a dar prioridad a los principios encapsulados en el bloque social demócrata, generando la llamada jurisprudencia con ínfulas critico-emancipatorias y contra-hegemónica, (de la que hablaría Uprimny y García) para, posteriormente, a través de un giro dar prevalencia a los principios del bloque económico neo-liberal. Este giro puede ser interpretado como un "intento de la Corte por seguir los lineamientos del Banco de la República y de otras entidades nacionales e internacionales debido al alto costo económico de los derechos fundamentales y los Desc" (Mejía \& Galindo, 2006). En esta misma línea, se encuentran algunos trabajos de Jairo Estrada (2010), donde sostiene la idea de un "constitucionalismo neoliberal", el cual habría emergido en los últimos diez años, y buscaría, entre otras cosas, constitucionalizar el modelo de sostenibilidad fiscal. En la formación de este, se incluyen tanto desarrollos legales como jurisprudenciales, los cuales, estos últimos, buscarían ponerle freno tanto a las acciones constitucionales de tutela como de inconstitucionalidad que ejerce la Corte Constitucional (Estrada, 2010). Según Daniel Libreros, este tipo de arquitectura jurídica obedece a la constante "presión del capital transnacional y de las Instituciones Financieras Internacionales" (Libreros, 2012, pág. 22). Así las cosas, afirma Gilberto Tobón Sanín, la constitución de 1991 -en este panorama- surge y se desarrolla dentro de una filosofía política que navega agitada en un amargo dualismo contingente: 
Lascarro Castellar, C; Lascarro Castellar, D; Caballero Palomino, S.

ideología social-demócrata y neoliberal. De ahí que, autores como Víctor Moncayo, en su conocido texto El Leviatan Derrotado, sostenga que, así como en los años treinta en Colombia se inició todo un proceso de ingeniería constitucional e institucional para permitir la instauración del keynesianismo y el Estado de bienestar, de la misma forma, pero en otro contexto y condiciones, fue necesario una reforma constitucional "armónica con la nueva época del capital", la cual "empezó a gestarse mucho antes" -de la expedición de la Constitución de 199110_ "cuando todavía no estaba de moda hablar de neoliberalismo y globalización" (Moncayo, 2004, pág. 200). El constitucionalismo en general, sostiene Moncayo siguiendo a Toni Negri, "tiene la pretensión de regular jurídicamente el poder constituyente, para bloquear su temporalidad constitutiva", y, en esa línea de argumentación, la Constitución actual, en medio de tantos debates, "se coló a lo largo de su articulado todo el espíritu de la nueva era del capitalismo" (Moncayo, 2004, pág. 203), denominada por Negri y Hardt Empire.

Una segunda lectura proviene de la teoría jurídica, y muestra como el activismo judicial es entendido desde la versión del tradicionalismo/positivismo nacional que se defiende frente a la embestida de nuevas formas de entender la actividad jurídica; formas como por las que ha optado el tribunal constitucional. "Esta resistencia básica del tradicionalismo al "nuevo derecho" se descompone en una serie de cargos. Entre estos cargos figuran (i) la dificultad contra mayoritaria, (ii) la deferencia que la Corte Constitucional debiera tener hacia las decisiones políticas y la asignación de recursos realizada mediante legislación pública o legislación privada, (iii) el papel secundario de la jurisprudencia (incluso si proviene de la Corte Constitucional) y (iv) y una cierta inclinación al originalismo interpretativo como forma específicamente pasivista de hermenéutica" (López, 2016, pág. 329). Estos cargos han sido formulados 1) desde el interior de la Corte y 2) por sectores externos a la misma. En el primer caso, provienen

${ }^{10}$ Consuelo Ahumada, ha sostenido que este tipo de políticas fueron implementadas desde finales de los ochenta y principio de los años noventa, las cuales "adoptaron programas de estabilización y de ajuste estructural prescrito por el Fondo Monetario Internacional” (Ahumada, 1996, pág. 29). 
Lascarro Castellar, c; L Lascarro Castellar, D; Caballero Palomino, s. 18

de magistrados de la Corte, quienes, en muchas ocasiones, por medio de los salvamentos de voto han manifestado su disenso, en este punto en concreto, frente a la labor del tribunal. Los ejemplos son variados; y podemos citar la Sentencia SU-342 de 1995, donde H. Herrera, F. Morón y V. Naranjo dejan por sentado los límites de la jurisdicción constitucional frente a temas de pactos o convenciones en derecho laboral, y el efecto limitado, inter partes y no erga omnes, de las sentencias de la Corte. En el segundo caso, varios doctrinantes han puesto de manifiesto esas limitaciones de legitimidad democrática que conllevan a que las decisiones de los jueces sean contra mayoritarias, por un lado, y, por el otro, a que estén basadas "en corazonadas, valores y principios generalísimos, doctrina que de alguna manera aplica la Corte Constitucional en sus sentencias modulativas y en desconocimiento expreso de textos constitucionales absolutamente claros, lo que hace que la corporación más que ser un intérprete de la carta, sea un nuevo legislador ilegítimo" (Tamayo, 2008, pág. 143).

Una tercera lectura provendría, al menos en parte, del denominado análisis económico del derecho. Esa perece ser la crítica del economicista Salomón Kalmanovitz (Kalmanovizt, 2001), quien ha señalado el supuesto carácter contra-mayoritario e inclinación populista de las decisiones de la Corte constitucional frente a temas económicos. El autor ha debatido, en contra vía a juristas pertenecientes al ámbito académico-jurisprudencial (como Uprimny, R. Arango), la pertinencia del activismo judicial, principalmente en materia de derechos sociales y cumplimientos de acciones de tutela. Kalmanovitz ha insistido en que juristas y economistas, a pesar de requerirse mutuamente, están en lenguajes distintos e incluso opuestos: "Según él, mientras que el razonamiento jurídico es deontológico porque busca determinar la conformidad de una acción con normas, sin tener en cuenta las consecuencias económicas, el razonamiento económico lleva a construir modelos simplificados de la realidad que permiten establecer las consecuencias económicas de las acciones de los agentes sobre distintas variables" (Lamprea, 2006, pág. 79). Por tanto, "las decisiones que ha tomado la honorable Corte Constitucional con relación al sistema de salud público, a la administración electoral y a otros entes estatales han repercutido en ampliar el gasto público en forma injustificada", y continua... "Es como si la Corte tuviera una chequera 
con una cuenta del Gobierno sobre la cual gira libremente sin límite, mientras que este debe consignar ingentes cantidades; pero cuando trata de cumplir y recaudarlas se encuentra que sus intenciones son inexequibles" (Kalmanovitz, 2001, pág. 124). En síntesis, el llamado de Kalmanovitz, dirigido a juristas y magistrados, es a complementar su razonamiento jurídico con argumentos consecuencialistas. Como señala Lamprea, casi todas estas críticas están relacionadas con una supuesta inclinación populista y el carácter contra-mayoritario de la Corte en sus pronunciamientos sobre temas económicos (Lamprea, 2006).

Hay una cuarta lectura, difícil de clasificar (de ahí que no la voy a nominar), pero que quisiera por lo menos poner de presente. Esta se puede estructurar desde el trabajo de Ricardo Sanín Restrepo. Básicamente lo que quiero señalar, es que para Sanín los límites del poder judicial en general y del activismo constitucional de la Corte en particular, saltan a la vista. Un diseño constitucional como el colombiano es incapaz de cuestionar las grandes estructuras de poder global. De hecho, realiza todo lo contrario; las encripta por medio del sofisticado lenguaje constitucional: "Con la encriptación del lenguaje tecno-legal, y, por ende, de los procedimientos, protocolos y decisiones, las manifestaciones sensibles del poder se vuelven ilegibles y con ellas el poder como fenómeno se torna indescifrable” (Mendez, 2014, pág. 67). Sanín (Sanín, 2012, pág. 15) expresa su reclamo a manera de preguntas: “¿Puede realmente una constitución inmersa en un intenso proyecto globalización capitalista transformar una sociedad política nacional y lograr una auténtica democracia?” ... “¿Puede una constitución alterar las gigantescas balanzas de poder mundial y los intereses que la determinan?... ¿Puede la constitución parases de frente ante el Consenso de Washington?”. La respuesta según el autor es obvia: no. Este tipo de lecturas parecen tomar una posición radical muy propia de algunos de los integrantes de la denominada "izquierda lacaniana" (Stavrakakis, 2010). Me refiero específicamente al filósofo esloveno Slavoj Žižek (2001). De ahí que para Sanín estas preguntas agónicas "no caben en el discurso constitucional y reflejan a su vez la despolitización del mismo. Sus respuestas parecen ser más bien, respuestas a preguntas falsas" (Lascarro, Lascarro, \& Martínez, 2012). 


\section{Referencias Bibliográficas}

Ahumada, C. (1996). El modelo neoliberal y su impacto en la sociedad colombiana. El Áncora Editores.

Baldi, C. (2013). Del constitucionalismo moderno al nuevo constitucionalismo latinoamericano descolonizador. REDHES.

Brown, W. (2003). Lo que se pierde con los derechos . En W. B. Willians, La crítica de los derechos. Bogotá: Universidad de los Andes e Instituto Pensar .

Encinales, N. (2011). Tercera generación de pensadores jurídicos en Colombia. Filosofía, Teoría y sociología del derecho en el campo jurídico colombiano. En Ó. M. Encinales, Elementos para una historia de la filosofía del derecho en Colombia. Bogotá: IBAÑEZ.

Jaramillo, I. C. (2003). Instrucciones para salir del discurso de los derechos . En W. B. willians, La crítica de los derechos. Bogotá: Universidad de los Andes e Instituto Pensar.

Kalmanovitz, S. (2001). Formas de pensar jurídicas y económicas. Revista de Derecho Público.

Kalmanovizt, S. (2001). Las consecuencias económicas de la Corte Constitucional. En Las instituciones y el desarrollo económico en Colombia. NORMA.

Lamprea, E. (2006). Derechos fundamentales y consecuencias económicas. Revista de Economía Institucional .

Lascarro, C. (2012). De la hegemonía (neo)constitucional a la estrategia del nuevo constitucionalismo latinoamericano . Revista Jurídicas. 
Lascarro, C. (2016). Estudios constitucionales post-91 en América Latina: (Casos Colombia, Bolivia y Ecuador) Paradigmas, problemáticas e itinerarios teóricos. Bogotá: Universidad NAcional de Colombia.

Lascarro, C., Lascarro, D., \& Martínez, L. (2012). Diálogos con Ricardo Sanín: crítica al constitucionalismo liberal contemporáneo. OXIMORA.

Lascarro, D. (2016). Teoría decolonial y constitucionalismo (andino): limites teóricos y nuevos horizontes. . Bogotá: Universidad Nacional de Colombia.

Libreros, D. (2012). Corte Constitucional y sostenibilidad fiscal. Fallo a favor del gran capital financiero. Revista de Izquierda.

López, D. (2016). El derecho de los jueces. Bogotá: LEGIS.

Lyotard, J. F. (1987). La condición posmoderna. Informe sobre el saber. REI.

Martínez, R., \& Viciano, R. (2010). Aspectos generales del nuevo constitucionalismo latinoamericano". En C. C. Ecuador, El nuevo constitucionalismo en América Latina. Ecuador: Corte Constitucional de Ecuador.

Médici, A. (2010). “Teoría constitucional y giro decolonial: Narrativas y simbolismos de las constitucionales. Reflexiones a propósito de la experiencia de Bolivia y Ecuador". . Revista de Estudiuos Críticos.

Mejía, Ó. (2009). Alienación, ideología y cosificación: una mirada desde las teorías críticas. . Pensamiento Jurídico.

Mejía, Ó., \& Galindo, C. (2006). La tercera Corte Constitucional: tensiones y desplazamientos. El giro de la Corte Constitucional de la jurisprudencia social a la neoliberal en la Constitución de 1991. Espacio Crítico.

Mendez, R. S. (2014). La Constitución encriptada. En J. Á. Magalaes, Democracia y constitucionalismo(s). Universidad Libre.

Moncayo, V. (2004). El Leviatan derrotado. NORMA. 
Ripoll, J. L. (2016). El derecho como conjuro legal. Bogotá: Siglo del Hombre Editores y Universidad de los Andes.

Rodríguez, C. R. (2012). Corte Constitucional y cambio social en Colombia. DEJUSTICIA.

Sanín, R. (2012). Teoría crítica constitucional II. Del existencialismo popular a la verdad de la democracia. Quito, Ecuador : Centro de Estudios y Difusión del Derecho Constitucional.

Stavrakakis, Y. (2010). La izquierda lacaniana. FCE.

Stephan, B. G. (1996). Economías fundacionales. Diseño del cuerpo. En B. G. Stephan. Caracas: Editorial Nueva Sociedad.

Tamayo, J. (2008). Crítica al nuevo derecho y a la interpretación constitucional de la corte constitucional. En P.-C. Centro de Investigaciones y estudios sociojurídicos, 3er Congreso nacional y 1er internacional de derecho constitucional. Tensiones contemporáneas del constitucionlismo. Centro de Investigaciones y estudios sociojurídicos.

Valencia, H. (1987). Cartas de batalla. Una crítica del consitucionalismo colombiano. Bogotá: CEREC.

Villegas, M. G. (2016). La eficacia simbóica del derecho. mSociología política del campo jurídico en América Latina. Bogotá: IEPRI y Universidad Nacional de Colombia .

Žižek, S. (2001). El espinoso sujeto. El centro ausente de la ontología política. Barcelona: PAIDOS. 